\title{
Decontamination Processing of Chlorpyrifos and Cypermethrin Residues in Cauliflower
}

\author{
Tanuja Banshtu* and Surender Kumar Patyal \\ Department of Entomology, Dr YS Parmar University of Horticulture and Forestry, Nauni, \\ Solan-173230 Himachal Pradesh, India \\ *Corresponding author
}

\begin{tabular}{|l|}
\hline Ke y w or d s \\
Curds, Processing, \\
Chlorpyrifos, \\
Cypermethrin
\end{tabular}

\section{A B S T R A C T}

Experiments of field and laboratory were carried out to evaluate the effect of different decontamination processes on reduction of chlorpyrifos and cypermethrin residues in cauliflower curds like washing, cooking, washing plus cooking and dipping in chemical solutions after application of ready-mix formulation Cannon 55EC (chlorpyrifos 50\% + cypermethrin 5\%) on the crop. Ready-mix formulation Cannon 55EC was applied twice at the rate of $1 \mathrm{ml} / \mathrm{L}$ at 15 days interval on cauliflower crop. Cauliflower curds were collected at 0 ( 2 hours), 3 and 7 days interval after the last spray and subjected to decontamination processes. Washing of zero day contaminated curd samples provided $37.41 \%$ relief from chlorpyrifos residues and $40.10 \%$ relief from cypermethrin residues. Cooking degraded chlorpyrifos residues up to $36.58-58.95 \%$ and cypermethrin residues by $45.45-66.31 \%$. Washing plus cooking removed chlorpyrifos and cypermethrin residues up to $70 \%$ as compared to other processes and proved to be the best technique in removing the residues. Washing of curds with $2 \% \mathrm{NaOH}$ solution reduced the chlorpyrifos residues up to 60.97$69.03 \%$, whereas washing with $0.05 \%$ solution of $\mathrm{HCl}$ reduced the chlorpyrifos residues up to $58.53-65.06 \%$. Similarly cypermethrin residues were reduced to $62.50-69.20 \%$ after treatment with $2 \% \mathrm{NaOH}$ solution and up to $63.44-66.97 \%$ after treatment with $0.05 \% \mathrm{HCl}$ solution.

\section{Introduction}

Vegetables are the inseparable component of Indian cuisine and are consumed throughout the country in different forms and preparations. They are the major source of vitamins and nutrients; hence they fulfil the requirements of our balanced diet (Chandra et al., 2015). Cauliflower (Brassica oleracea var. botrytis L.) is an important cash crop of Himachal Pradesh which is infested by a large number of insect-pests and diseases (Sharma and Bhalla, 1964; Sharma, 1975; Bhalla and Pawar, 1977). The key pests of cauliflower are diamond back moth, leaf eating caterpillar and aphids (Regupathy et al., 1985; Patel et al., 1999) thus affecting both the quantity and quality of curds. In a desperate bid to save the crop farmers sometime apply the pesticide repeatedly and at higher doses hence the repeated and intensive use of insecticides have lead to the development of resistance in insect pests (Gaganpreet et al., 2017). In Himachal Pradesh pesticides such as chlorpyrifos and 
cypermethrin have been used extensively by the farmers to control these major insect-pests of cauliflower both individually and as readymix formulations. Since, the effect of pesticide mixtures is considered more toxic than their individual components, extra care should be taken to reduce the health hazards to the consumers (Regupathy et al., 2004). The application of these pesticides near to harvest can leave residues on the curds which may be harmful to the consumers (Banshtu et al., 2015).

Cauliflower is consumed as raw and cooked vegetable; hence chances of carrying pesticide residues to the consumers are more (Raj et al., 1991). Hence Pesticide residues in cauliflower are of major concern to consumers due to their negative health effects. They have been found in both raw and processed fresh produce. There have been various reports suggesting use of different simple household processes in dislodging pesticide residues from food commodities thus making them safe for human consumption (Sharma et al., 1994; Aktar et al., 2009; Chavarri et al., 2005; Dejonckheere et al., 1996; Elkins, 1989; Krol et al., 2000; Schattenberg et al., 1996). Operations such as Washing, peeling, blanching and cooking play a crucial role in the reduction of residues (Elkins, 1989; Kaushik et al., 2009). Each operation has a cumulative effect on the reduction of the pesticides (Geisman et al., 1975).

So in the present scenario it is very important that some pragmatic solution should be developed to tackle this problem of food safety. Food safety is an area of growing concern worldwide on account of its direct bearing on human health. The presence of harmful pesticide residues in food such as cauliflower has caused a great concern among the consumers. Therefore, the present investigations were contemplated with the objective to study the effect of different decontamination processes in curds for the reduction of chlorpyrifos and cypermethrin residues after the application of ready-mix formulation on cauliflower crop in the field. Hence the techniques used in the present study focused on commercial and home processing of cauliflower and they included washing alone, washing with chemicals, cooking and washing followed by cooking.

\section{Materials and Methods}

\section{Chemicals and reagents}

Ready-mix formulation Cannon 55EC containing $50 \%$ chlorpyrifos and 5\% cypermethrin was obtained from M/S Nagarjuna Agrichem Ltd. and reagents like acetone, dichloromethane, hexane, toluene, sodium chloride, sodium sulphate anhydrous (AR grade), Celite 545 and Florisil were all procured from M/S Merck Specialities, Mumbai. Activated charcoal decolorizing powder was obtained from M/S Darmstadt, Germany. All common solvents were redistilled in an all-glass apparatus before use.

\section{Field trials}

Cauliflower (Brassica oleracea var. botrytis L.) was raised during 2010 at Entomological Farm, Dr YS Parmar University of Horticulture and Forestry, Nauni, Solan, Himachal Pradesh following recommended agronomic practices (Anonymous, 2010).

The experiment was conducted in randomized block design (RBD) with three replications for each treatment. The first application of Cannon 55EC @ $1 \mathrm{ml} / \mathrm{L}$ of water was made at curd formation stage followed by second application at an interval of 15 days. In control plots, only water was sprayed. Pesticide was sprayed as foliar application in three replications with the help of a knapsack sprayer, fitted with a hollow cone nozzle. 


\section{Sampling procedure}

Curd samples $(1 \mathrm{~kg})$ from each replication were collected randomly at 0 ( 2 hours after spray), 3 and 7 days intervals after last foliar application. The samples from each replication were collected randomly, packed in bags and brought to the laboratory for processing.

\section{Decontamination processes}

Samples collected from the field were subjected to different decontamination processes viz. washing, cooking and washing followed by cooking (Patyal et al., 2004).

\section{Washing}

Cauliflower curds were washed under running tap water and hand rubbed for 2 minutes.

Cauliflower curds samples were dipped in lukewarm water $\left(50^{\circ} \mathrm{C}\right)$ for 5 minutes and then, placed on filter papers for drying.

Curd samples were dipped in $2 \% \mathrm{NaCl}(\mathrm{w} / \mathrm{v})$ solution for 5 minutes followed by tap water washing.

Curd samples were dipped in 2\% lukewarm salt solution $(\mathrm{w} / \mathrm{v})$ for 5 minutes followed by water washing.

Curd samples were dipped in $0.05 \% \mathrm{HCl}(\mathrm{v} / \mathrm{v})$ for 5 minutes, followed by water wash.

Curd samples were dipped in $2 \%(\mathrm{w} / \mathrm{v})$ sodium hydroxide solution for 5 minutes, followed by washing with water.

\section{Cooking}

Open pan cooking: Unwashed samples from each replication were chopped and put in an open pan of 1 litre capacity containing $500 \mathrm{ml}$ water and boiled till softness (10-15 minutes).
Steam cooking: Samples were chopped and steamed for 5 minutes in a pressure cooker.

Microwave cooking: Curd samples were kept in microwave for 5 minutes for cooking at $1400 \mathrm{~W}$ power output.

\section{Washing followed by cooking}

Washing + cooking: Curd sample were first washed by hand rubbing under a stream of running tap water for 2 minutes, followed by boiling in an open pan of 1 litre capacity containing $500 \mathrm{ml}$ water till soft (10-15 minutes).

Washing + steam cooking: Sample were washed under running tap water and steamed for 5 minutes in a pressure cooker.

Washing + microwave cooking: Samples were first washed under the tap water and then, placed in microwave for 5 minutes for cooking at $1400 \mathrm{~W}$ power output.

After completing decontamination process, samples were extracted and cleaned up according to the method of Sharma (2007).

\section{Extraction and cleanup}

The samples were processed and analyzed at the Pesticide Residue Analysis Laboratory, Department of Entomology, Dr YS Parmar University of Horticulture and Forestry, Nauni, Solan, Himachal Pradesh. Processed cauliflower curd samples were homogenised in a domestic mixture.

A representative $100 \mathrm{~g}$ homogenised sample was taken up with $200 \mathrm{ml}$ acetone in a $500 \mathrm{ml}$ conical flask and kept for overnight. The extract was filtered through Buchner funnel by fitting a Whatman No. 1 filter paper. An aliquot of $60 \mathrm{ml}$ (30 g equivalent) of sample was transferred to 1 litre separatory flask and 
extracted with $200 \mathrm{ml}$ mixture of hexane and dichloromethane $(1: 1, \mathrm{v} / \mathrm{v})$. The lower aqueous phase was transferred to another 1 litre separatory funnel containing ten millilitre saturated sodium chloride solution and partitioned twice with $100 \quad \mathrm{ml}$ dichloromethane. Lower aqueous phase was discarded and upper organic phase was pooled with first organic fraction. Pooled organic phase was passed through anhydrous sodium sulfate and evaporated to dryness at $45^{\circ} \mathrm{C}$ by using vacuum rotary evaporator. Finally, the residues were taken up in $3 \mathrm{ml}(1+2)$ acetone for cleanup. Samples for cypermethrin residues were cleaned up on Florisil column and chlorpyrifos samples were cleaned up on charcoal column.

First sample fraction of $1 \mathrm{ml}$ was diluted with $10 \mathrm{ml}$ of acetone: hexane (1:9) mixture, loaded on the $4 \mathrm{~g}$ activated Florisil column overlaid with $2 \mathrm{~g}$ sodium sulfate. The column was eluted with $50 \mathrm{ml}$ eluent $(50 \%$ dichloromethane: $\quad 48.5 \%$ hexane: $1.5 \%$ acetonitrile). Eluant was evaporated to dryness, residues were dissolved in $1 \mathrm{ml} \mathrm{n}$ hexane and injected into gas chromatograph.

Two millilitres of sample fraction was loaded in a charcoal column which was prepared by placing one inch layer of Celite 545, $6 \mathrm{~g}$ adsorbent mixture (1:4 w/w Charcoal: Celite 545) and then, overlaid with $2 \mathrm{~g}$ sodium sulfate. The column was eluted with $200 \mathrm{ml}$ of 2:1 acetone: dichloromethane mixture. Eluant was evaporated to dryness, residues were dissolved in $2 \mathrm{ml} \mathrm{n}$-hexane and injected $1 \mu \mathrm{l}$ into a gas chromatograph.

\section{Residue estimation}

Residues of chlorpyrifos and cypermethrin were estimated by using Gas-Chromatograph (Agilent 6890N) having ECD detector and DB-5 Ultra Performance Capillary column (Cross-linked Methyl Silicon, length $30 \mathrm{~m}$,
$0.25 \mathrm{~mm}$ internal diameter with $0.25 \mu \mathrm{m}$ film thickness). Oven temperature was programmed as: $100^{\circ} \mathrm{C}$ for 1 minute, $30^{\circ} \mathrm{C} /$ minute up to $150^{\circ} \mathrm{C}, 3^{\circ} \mathrm{C} /$ minute up to $205^{\circ} \mathrm{C}$ and finally $260^{\circ} \mathrm{C}$ at rate of $10^{\circ} \mathrm{C} /$ minute. Injection port and electron capture detector (ECD) temperature were kept at $250^{\circ} \mathrm{C}$ and $300^{\circ} \mathrm{C}$, respectively.

Chlorpyrifos and cypermethrin residues $(\mathrm{mg} / \mathrm{kg})$ were determined for each replication and then mean residues were calculated. Per cent relief from residues in each treatment was calculated from the mean residues, by the following equation:

$\%$ relief $=100-($ Residue in processed sample $(\mathrm{mg} / \mathrm{kg})$ / Residue in unprocessed sample $(\mathrm{mg} / \mathrm{kg}))$ X 100)

\section{Validation of analytical method}

The analytical method employed to estimate chlorpyrifos residues was validated by spiking the control curd samples at four different concentrations viz., $0.01,0.05,0.10$ and 0.5 $\mathrm{mg} / \mathrm{kg}$ whereas, cypermethrin samples were spiked at $0.05,0.10,0.50$ and $1.0 \mathrm{mg} / \mathrm{kg}$ concentrations. Recovery of chlorpyrifos was between $90.00-94.00 \%$ with relative standard deviation (RSD) of $0.112-1.030 \%$ in fruits and recovery of cypermethrin was between 90.00 $92.00 \%$ with RSD of $0.062-0.988 \%$ (Table 1 ).

\section{Results and Discussion}

\section{Effect of washing}

Washing is the most common form of processing which is a preliminary step in both household and commercial preparation. Loosely held residues of several pesticides are removed with reasonable efficiency by varied types of washing processes (Street, 1969). Washing of 0 day sampled cauliflower curds under running tap water provided $37.41 \%$ 
relief whereas 33.80 and $29.26 \%$ relief from chlorpyrifos residues was observed in 3 and 7 day old samples, respectively (Figure 1). Similar observations were recorded after washing of cauliflower curds treated with cypermethrin (Figure 3). Aktar et al., (2010) reported that washing of cabbage head under running tap water removed 27.72-32.48\% quinalphos residues which are in accordance with my findings. Similarly, Singh et al., (2004) also found that washing of okra fruits with tap water could remove the residues of cypermethrin to the extent of $36.25-42.76 \%$. The initial diazinon residue level $(0.822 \mathrm{ppm})$ on cucumbers was decreased by $22.3 \%$ by washing for 15 seconds rubbing under running water (Cengiz et al., 2006).

Lukewarm water washing of 0 day sampled cauliflower curds provided $41.21 \%$ relief whereas 39.29 and $36.58 \%$ relief from chlorpyrifos residues was observed in 3 and 7 days old samples, respectively (Fig. 1). Similar observations were recorded after washing of cauliflower curds treated with cypermethrin (Fig. 2) which are in accordance with Kanta et al., (1998) who reported 7-38 per cent reduction of alpha-cypermethrin residues by lukewarm water washing of cauliflower curds. Kumari (2008) also reported 32-100 per cent reduction of OP's insecticide residues by lukewarm water of cauliflower.

\section{Chemical washing}

Washing of treated cauliflower curds with sodium hydroxide and hydrochloric acid provided a good relief from chlorpyrifos and cypermethrin in comparison to washing with sodium chloride and lukewarm sodium chloride solution. It may be due to hydrolytic property of chlorpyrifos and cypermethrin in strong acids and alkalis (Tomlin, 1995). Sodium hydroxide provided $69.03 \%$ and $70.14 \%$ relief from chlorpyrifos and cypermethrin, respectively. Dip treatment of cauliflower curds with hydrochloric acid gave $65.06 \%$ relief from chlorpyrifos and $69.43 \%$ from cypermethrin residues. The present findings are in agreement with Patyal et al., (2004) who found that washing of treated apple fruits with $2 \%(\mathrm{w} / \mathrm{v}) \mathrm{NaOH}$ and $0.05 \%$ (v/v) $\mathrm{HCl}$ gave 77.06 and $75.96 \%$, relief respectively from endosulfan residues.

Marshall (1982) also reported that unwashed samples of green beans contained an average of $1.49 \mathrm{ppm}$ of EBDC (Ethylenebis dithiocarbamates) and very low levels of its metabolite ethylenethiourea (ETU). Washing of beans in cold water for 2 min removed $45 \%$ of EBDC but did not affect the levels of ETU whereas, the wash with alkaline hypochlorite followed by dipping in dilute sodium sulfite left no detectable residues of EBDC or ETU on the beans.

Dipping of cauliflower curd samples in $2 \%$ sodium chloride solution $(\mathrm{w} / \mathrm{v})$ reduced chlorpyrifos and cypermethrin residues to $43.03 \%$ and $46.21 \%$ whereas lukewarm sodium chloride solution reduced residues to $51.18 \%$ and $61.13 \%$ respectively which is in agreement with the findings of Mukherjee et al., (2006) also observed that dipping of cauliflower curds in $1 \%$ brine solution followed by washing reduced the residues by $39.6 \%$ while in case of hot $1 \%$ brine solution, the reduction was $55.0 \%$.

\section{Cooking}

Application of heat to the food commodities is commonly done through ordinary cooking, pressure cooking, microwave cooking, frying, sterilization and canning. The effect of different cooking processing on removal of chlorpyrifos and cypermethrin residues in cauliflower was studied (Figure 1 and 2). In all of the processes, cooking with pressure cooking was found to be more effective than in others. 
Fig.1 Per cent relief from chlorpyrifos residues from different decontamination processes $(\mathrm{W}=$ Tap water washing, $\mathrm{LW}=$ Luke warm, $\mathrm{OPC}=$ Open pan cooking, $\mathrm{PC}=$ Pressure cooking, $\mathrm{MC}=$ Microwave cooking)

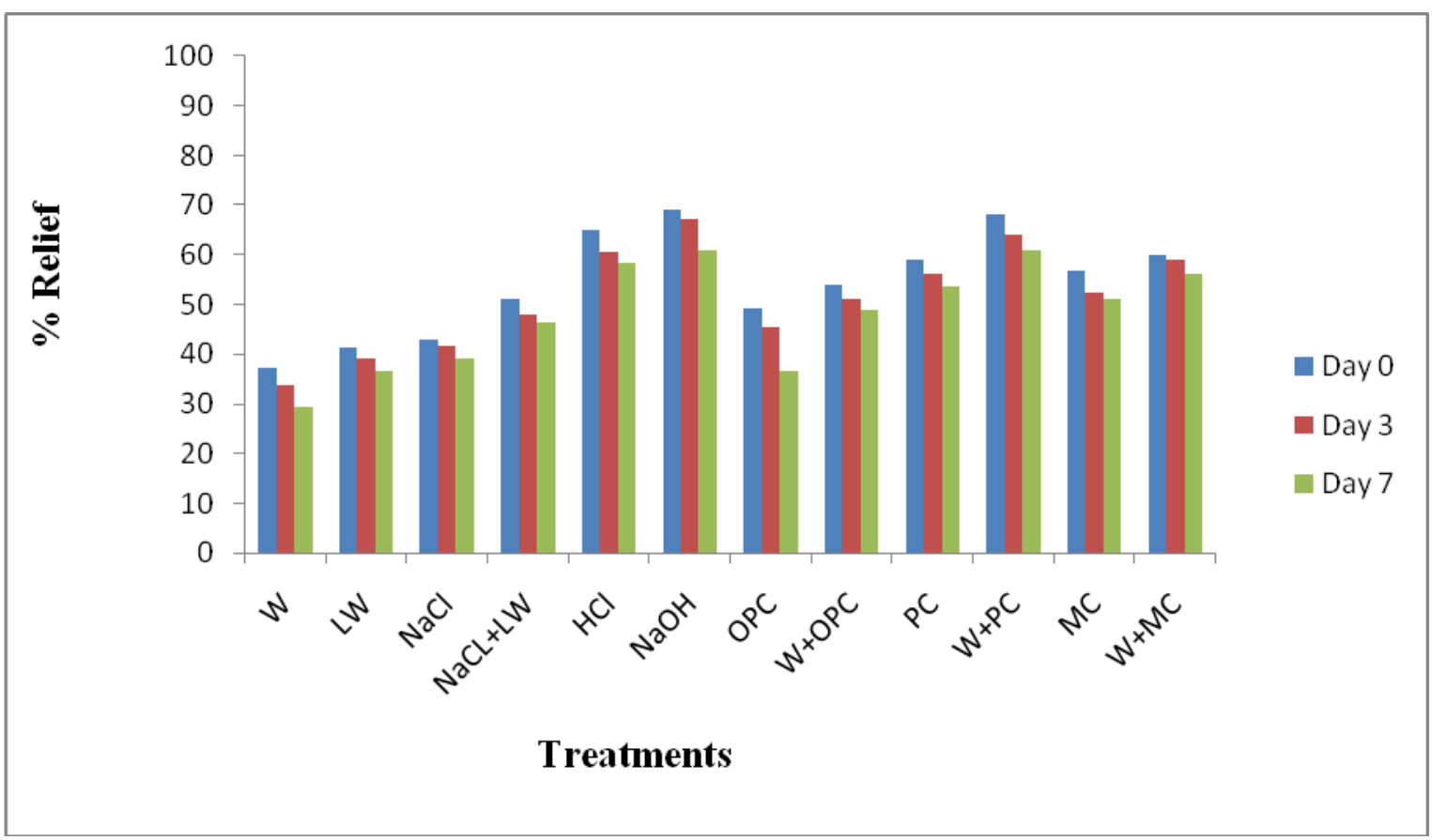

Fig.2 Per cent relief from cypermethrin residues from different decontamination processes (W= Tap water washing, $\mathrm{LW}=$ Luke warm, $\mathrm{OPC}=$ Open pan cooking, $\mathrm{PC}=$ Pressure cooking, $\mathrm{MC}=$ Microwave cooking)

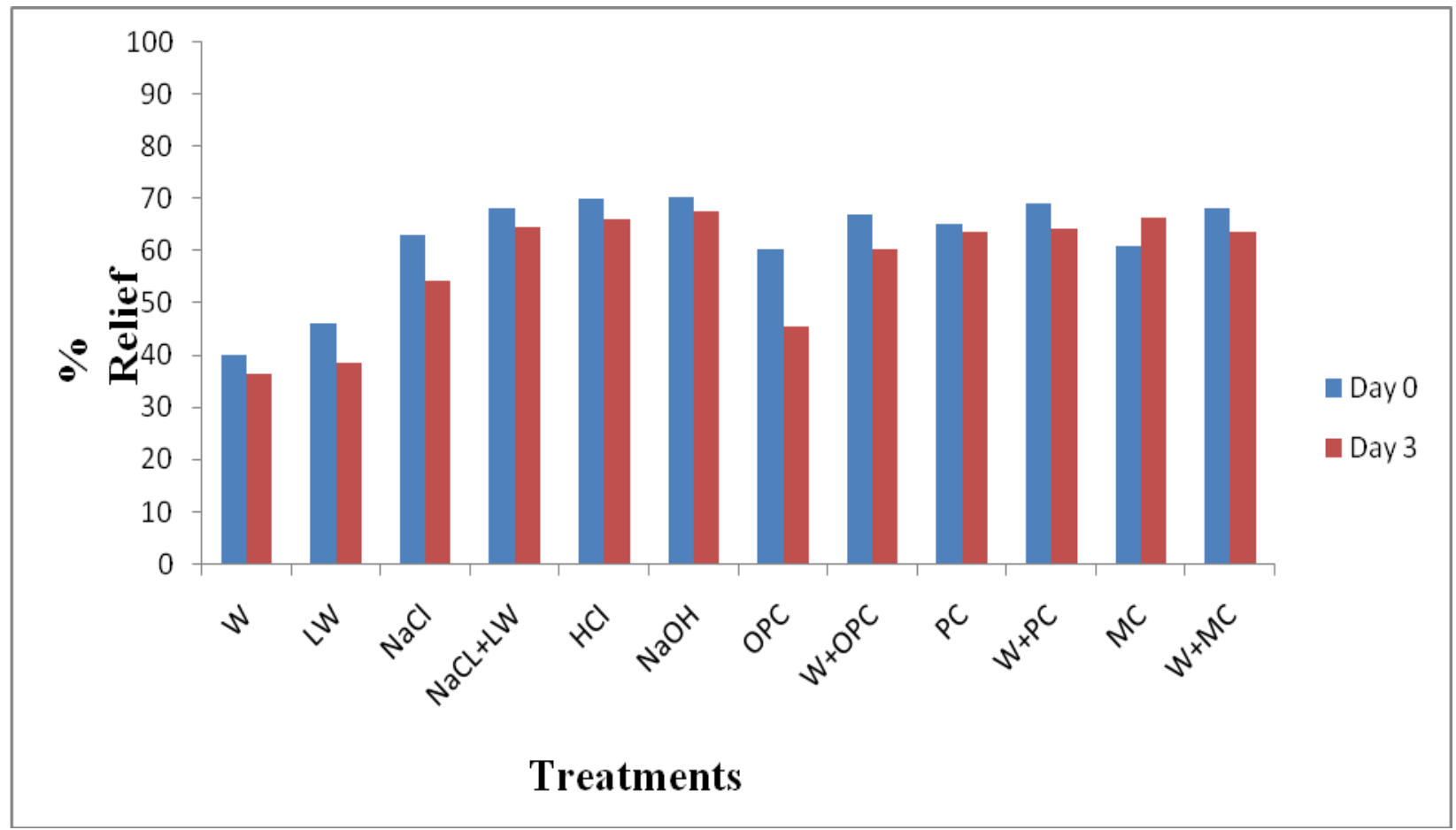


Table.1 Recovery of chlorpyrifos and cypermethrin from cauliflower curds

\begin{tabular}{|c|c|c|c|}
\hline \multirow[t]{2}{*}{ Insecticides } & \multicolumn{3}{|c|}{ Cauliflower curds } \\
\hline & $\begin{array}{l}\text { Fortification level, } \\
\qquad(\mathrm{mg} / \mathrm{kg})\end{array}$ & $\begin{array}{c}\text { Mean recovery } \\
(\%)\end{array}$ & $\begin{array}{l}\text { Relative standard } \\
\text { deviation (\% RSD) }\end{array}$ \\
\hline \multirow[t]{4}{*}{ Chlorpyrifos } & 0.01 & 90.00 & 1.030 \\
\hline & 0.05 & 92.00 & 0.987 \\
\hline & 0.10 & 93.00 & 0.858 \\
\hline & 0.50 & 91.00 & 0.178 \\
\hline \multirow[t]{4}{*}{ Cypermethrin } & 0.05 & 90.00 & 0.988 \\
\hline & 0.10 & 90.00 & 0.525 \\
\hline & 0.50 & 90.00 & 0.160 \\
\hline & 1.00 & 92.00 & 0.062 \\
\hline
\end{tabular}

Pressure cooking reduced the residues up to $58.95 \%$. These results are in accordance with the findings of Muthukumar et al., (2010) who also reported that pressure cooking was the most effective in reducing both $\alpha$ - and $\beta$ endosulfan by $64.59 \%$ and $61.60 \%$ as compared to boiling and microwave cooking.

Cooking of cauliflower curds in open pan or under pressure or in the microwave resulted in $50-60 \%$ relief from chlorpyrifos and cypermethrin residues. The findings are in agreement with Dikshit (2001) who observed that process of steaming dislodged the cypermethrin residues by $63-74 \%$ on stored pulses treated at 3 and $5 \mathrm{mg} / \mathrm{kg}$ levels. The disappearance of pesticide residues from boiling extract could be due to decomposition by the effect of heat, the stronger adsorption of pesticide onto plant tissues and or/the poor solubility of pesticides in water (Abou and Abou 2001; Ali, 1983). Walia et al., (2010) reported that microwave cooking reduced cypermethrin residues to the extent of 40.89 per cent in brinjal sprayed at 0.001 per cent concentration. Hence, processes involving heat can increase volatilization, hydrolysis or other chemical degradation and thus, reduce residue levels (Holland et al., 1994).

\section{Washing followed by cooking}

Washing is generally the first step in various types of treatments which are given to food commodities in combinations like washing followed by cooking, washing and drying, washing and peeling and washing, peeling and juicing to allow for effective decontamination from pesticides (Kaushik et al., 2009).

Washing of cauliflower curds followed by cooking lead to more than $65 \%$ removal of chlorpyrifos and cypermethrin residues (Figure 1 and 2). Similarly, Mukherjee et al., 2006 also reported that washing of cauliflower heads under running tap water removed $27.9 \%$ chlorpyrifos residues, cooking reduced residues to $41.4 \%$ and washing + cooking further reduced residues to 66.7\%. Aktar et al., (2010) also reported that washing plus cooking of cabbage heads reduce more quinalphos residues (66.45$68.19 \%$ ) in comparison to washing alone (41.30-45.20\%).

A critical analysis of whole decontamination data revealed that the washing plus pressure cooking removed much higher residues from 
contaminated curds as compared to the simple washings. Although, sodium hydroxide and hydrochloric acid treatments were superior over all other decontamination processes but such treatments can be used in the industries where large quantity of vegetables are processed for decontamination. Washing of vegetables with water followed by pressure cooking removed maximum residues upto $70 \%$ as compared to the other processes and proved good household practice.

\section{References}

Abou AAAK and Abou DMA. 2001. Pesticide residues in some Egyptian spices and medicinal plants as affected by processing. Food Chemistry 72: 439-445

Aktar MW, Dwaipayan S, Mariappan P and Ashim C. 2009. Risk assessment and degradation of an insecticide (chlorpyriphos): a decontamination study under different culinary processes in/on cabbage. Kasetsart Journal Natural Sciences 43(2): 231-238

Aktar MW, Dwaipayan S, Purkait S and Chowdhury A. 2010. Risk assessment and decontamination of quinalphos under different culinary processes in cabbage. Environmental Monitoring and Assessment 163: 369-377

Ali SL. 1983. Bestimmung der pestiziden Ruckstande und anderer bedenklicher eruntreinigungen-wie toxische Metallspuren in Arzneipflanzen1. Mitt: Pestizid-Ruckstande in Arzneidrofen. Pharmazie Industrial 45: 1154-1156

Anonymous. 2010. Package and Practices for Vegetable Crops. Directorate of Extension Education, Dr. Y.S Parmar University of Horticulture and Forestry, Solan. p. 294

Banshtu T, Patyal SK and Chandel RS. 2015. Persistence of profenofos and cypermethrin in tomato grown under mid hill conditions of Himachal Pradesh. The Ecoscan 9(3\&4): 755-759

Bhalla OP and Pawar AD. 1977. A survey study of insect and non-insect pests of economic importance in Himachal Pradesh. Tiku and Tiku, Kitab Mahal, 80p.

Cengiz MF, Certel M, Karakas $\mathrm{B}$ and Gocmen, H. 2006. Residue contents of DDVP (Dichlorvos) and diazinon applied on cucumbers grown in greenhouses and their reduction by duration of a pre-harvest interval and post-harvest culinary applications. Food Chemistry 98: 127-135.

Chandra S, Kumar M, Mahindrakar AN and Shinde LP. 2015. Effects of household processing on reduction of pesticide residues in brinjal and okra. International Journal of Advances in Pharmacy, Biology and Chemistry 4(1): 98-102

Chavarri MJ, Herrera A and Arino A. 2005. The decrease in pesticides in fruit and vegetables during commercial processing. International Journal of Food Science and Technology 40(2): 205-211

Dejonckheere W, Steurbaut W, Drieghe S, Verstraeten R and Braeckman H. 1996. Pesticide residue concentrations in the Belgian total diet, 1991-1993. Journal of AOAC International 79(2): 520-528

Dikshit AK. 2001. Persistence of cypermethrin on stored pulses and its decontamination. Pesticide Research Journal 13(2): 141-146

Elkins ER. 1989. Effect of commercial processing on pesticide residues in selected fruits and vegetables. Journal of the Association of Official Analytical Chemists 72(3): 533-535

Gaganpreet SB, Patyal SK and Banshtu T. 2017. Persistence of acephate, profenofos and triazophos residues in 
brinjal fruits and soil. The Bioscan 12(1): 115-119

Geisman JR, Gunther FA and Gunther JD. (eds.). 1975. Reduction of pesticide residues in food crops by processing. Residue reviews. Residues of pesticides and other contaminants in the total environment 54, pp. 43-54

Holland PT, Hamilton D, Ohlin B, and Skidmore MW. 1994. Effects of storage and processing on pesticide residues in plant products. IUPAC Reports on Pesticides 31. Pure and Applied Chemistry 66(2): 335-356

Kanta M, Kumari B and Kathpal TS. 1998. Persistence and decontamination of alphamethrin residue in cauliflower at two different temperatures. Pesticide Research Journal 10(2): 246-250.

Kaushik G, Satya S and Naik SN. 2009. Food processing a tool to pesticide residue dissipation -a review. Food Research International 42: 26-40.

Krol WJ, Arsenault TL, Pylypiw HM and Mattina MJI. 2000. Reduction of pesticide residues on produce by rinsing. Journal of Agricultural and Food Chemistry 48(10): 4666-4670.

Kumari B. 2008. Effects of household processing on reduction of pesticide residues in vegetables. Journal of Agricultural and Biological Science 3(4): 46-51.

Marshall WD. 1982. Preprocessing oxidative washes with alkaline hypochlorite to remove ethylenebis (dithiocarbamate) fungicide resides from tomatoes and green beans. Journal of Agricultural and Food Chemistry 30(4): 649-652.

Mukherjee P, Kole RK, Bhattacharyya A and Banerjee H. 2006. Reduction of chlorpyrifos residues from cauliflower by culinary processes. Pesticide Research Journal 18(1): 101-103.

Muthukumar M, Sudhakar RK, Reddy NC, Reddy KK, Reddy GA, Reddy JD and
Kondaiah N. 2010. Detection of cyclodiene pesticide residues in buffalo meat and effect of cooking on residual level of endosulfan. Journal of Food Science and Technology 47(3): 325329.

Patel BA, Shah PG, Raj MF, Patel BK, Patel JA and Talathi JG. 1999. Chorpyriphos residues in/on cabbage and brinjal. Pesticide Research Journal 11(2): 194196

Patyal SK, Lakhanpal AK, Nath A and Sharma PC. 2004. Effect of processing on endosulfan residues in apple. Journal of Food Science and Technology Mysore 41(3): 316-319.

Raj MF, Shah PG, Patel BK and Patel JR. 1991. Endosulfan residues in tomato and brinjal fruits. Pesticide Research Journal 3(2): 135-138.

Regupathy A, Habcebullah B and Balasubramania M. 1985. Dissipation of insecticides applied to control Plutella xyllostella citrus and Spodoptera litura, Faber in cauliflower. Pesticides 19(9): 53.

Regupathy A, Ramasubramanian $\mathrm{T}$ and Ayyasamy R. 2004. Rationale behind the use of insecticide mixtures for the management of insecticide resistance in India. Food, Agriculture \& Environment 2(2): 278-284.

Schattenberg HJ, Geno PW, Hsu JP, Fry WG and Parker RP. 1996. Effect of household preparation on levels of pesticide residues in produce. Journal of AOAC International 79(6): 1447-1453.

Sharma ID, Nath A and Dubey JK. 1994. Persistence of mancozeb (Dithane M45 ) in some vegetables and efficacy of decontamination processes. Journal of Food Science and Technology 31(3): 215-218.

Sharma KK. 2007. Pesticide Residue Analysis Manual. Directorate of Information and Publications of Agriculture, Indian 
Council of Agricultural Research, Krishi Anusandhan Bhavan, Pusa, New Delhi, p. 294.

Sharma PL and Bhalla OP. 1964. Survey study of insect pests of economic importance in Himachal Pradesh. Indian Journal of Entomology 26: 318-331.

Sharma VK. 1975. Survey of insect pests of, off season tomato under mid hill conditions. M.Sc. Thesis submitted to Himachal Pradesh University Shimla, India. 1-126 pp.

Singh SP, Kiran K, Sanjay K and Tanwar RS. 2004. Dissipation and decontamination of cypermethrin and fluvalinate residues in okra. Pesticide Research Journal 16(2): 65-67.

Street JC. 1969. Methods of removal of pesticide residues. Canadian Medical Association Journal 100: 154-160.

Tomlin C. 1995. The Pesticide Manual. A World Compendium. British Crop Protection Council, p. 388.

Walia S, Boora P and Kumari B. 2010. Effect of processing on dislodging of cypermethrin residues on brinjal. Bulletin of Environmental Contamination and Toxicology 84(4): 465-468.

\section{How to cite this article:}

Tanuja Banshtu and Surender Kumar Patyal. 2018. Decontamination Processing of Chlorpyrifos and Cypermethrin Residues in Cauliflower. Int.J.Curr.Microbiol.App.Sci. 7(05): 859-868. doi: https://doi.org/10.20546/ijcmas.2018.705.105 